\title{
Proteomic and metabolomic analysis reveals rapid and extensive nicotine detoxification ability in honey bee larvae
}

Esther E. du Rand ${ }^{a, b *}$, Hannelie Human ${ }^{b}$, Salome Smit $^{c}$, Mervyn Beukes ${ }^{a}$, Zeno Apostolides $^{a}$, Susan W. Nicolson ${ }^{b}$ and Christian W.W. Pirk ${ }^{b}$

${ }^{\mathrm{a}}$ Department of Biochemistry, University of Pretoria, Private Bag X20, Hatfield 0028, South Africa

${ }^{\mathrm{b}}$ Department of Zoology and Entomology, University of Pretoria, Private Bag X20, Hatfield 0028, South Africa

${ }^{c}$ Proteomics Unit, Central Analytical Facility, Stellenbosch University, Private Bag X1, Matieland 7602, South Africa

\section{*Corresponding author}

Esther E. du Rand (Ezette)

Department of Zoology and Entomology, University of Pretoria, Private Bag X20, Hatfield 0028, South Africa

Tel: +27845859954

Email: ezette.durand@up.ac.za

Email addresses of other authors:

Hannelie Human: hhuman@zoology.up.ac.za

Salome Smit: $\underline{\text { salome@ anatech.co.za }}$

Mervyn Beukes: mervyn.beukes@up.ac.za

Zeno Apostolides: zeno.apostolides@up.ac.za

Susan W. Nicolson: swnicolson@zoology.up.ac.za

Christian W. Pirk: cwwpirk@zoology.up.ac.za 


\begin{abstract}
Despite potential links between pesticides and bee declines, toxicology information on honey bee larvae (Apis mellifera) is scarce and detoxification mechanisms in this development stage are virtually unknown. Larvae are exposed to natural and synthetic toxins present in pollen and nectar through consumption of brood food. Due to the characteristic intensive brood care displayed by honey bees, which includes progressive feeding throughout larval development, it is generally assumed that larvae rely on adults to detoxify for them and exhibit a diminished detoxification ability. We found the opposite. We examined the proteomic and metabolomic responses of in vitro reared larvae fed nicotine (an alkaloid found in nectar and pollen) to understand how larvae cope on a metabolic level with dietary toxins. Larvae were able to effectively detoxify nicotine through an inducible detoxification mechanism. A coordinated stress response complemented the detoxification processes, and we detected significant enrichment of proteins functioning in energy and carbohydrate metabolism, as well as in development pathways, suggesting that nicotine may promote larval growth. Further exploration of the metabolic fate of nicotine using targeted mass spectrometry analysis demonstrated that, as in adult bees, formation of 4-hydroxy-4-(3-pyridyl) butanoic acid, the result of 2'C-oxidation of nicotine, is quantitatively the most significant pathway of nicotine metabolism. We provide conclusive evidence that larvae are capable of effectively catabolising a dietary toxin, suggesting that increased larval sensitivity to specific toxins is not due to diminished detoxification abilities. These findings broaden the current understanding of detoxification biochemistry at different organizational levels in the colony, bringing us closer to understanding the capacity of the colony as a superorganism to tolerate and resist toxic compounds, including pesticides, in the environment.
\end{abstract}

\title{
Key words
}

Apis mellifera, larvae, nicotine, detoxification, energy metabolism 


\section{Introduction}

Honey bees (Apis mellifera L.) develop through complete metamorphosis. What differentiates honey bees from solitary holometabolous insects is that they feed their larvae progressively throughout larval development and have a nutrition-based mechanism of caste determination (Buttstedt et al., 2016; Winston, 1987). Larvae are primarily fed jelly produced by the hypopharyngeal and mandibular glands of nurse bees (Haydak, 1970). From day three, larvae destined to become workers are fed some pollen and honey in addition (Haydak, 1970) and even receive a little nectar (DeGrandi-Hoffman and Hagler, 2000; Nixon and Ribbands, 1952). Consequently, larvae are directly exposed to secondary metabolites and pesticides present in floral nectar and pollen (Adler et al., 2012; Blacquière et al., 2012; Chauzat et al., 2006, 2011). Secondary metabolites and pesticides have also been detected in bee bread (stored pollen mixed with glandular secretions), honey and royal jelly (Chauzat et al., 2006, 2011; Isidorov et al., 2009; Kretschmar and Baumann, 1999; London-Shafir et al., 2003; Mullin et al., 2010; Smodiš Škerl et al., 2010). In addition, high levels of pesticide residues were also measured in wax samples from the brood nest where larvae develop (Chauzat and Faucon, 2007; Mullin et al., 2010). Subsequently, larvae are exposed orally and topically to naturally occurring toxins as well as synthetic toxicants.

Despite the potential links between pesticides and bee declines, toxicology information on honey bee larvae is scarce and detoxification mechanisms in this development stage are virtually unknown. Due to the characteristic intensive brood care displayed by honey bees (Heimken et al., 2009), it is generally assumed that the larvae rely on adult bees to detoxify for them and that this development stage exhibits a diminished ability to detoxify dietary toxins. Most published work in this area tends to focus exclusively on adult bees and on the acute toxicity of dietary toxins. Compared to the extensive research on adults, only a few studies have examined the sublethal effects or larval responses to pesticide or plant secondary metabolite exposure (Arnold et al., 2014; Aupinel et al., 2007; Davis, 1989; Gregorc and Ellis, 2011; Mao et al., 2015; Singaravelan et al., 2006; Zhu et al., 2014). Where sublethal effects of secondary plant metabolites are concerned, ecologically relevant concentrations of nicotine (found in the pollen and nectar of Nicotiana species) did not impact survival of larval honey bees negatively (Human et al., 2014; Singaravelan et al., 2006). Micro-colonies of bumblebees provided with lupanine treated pollen (an alkaloid found in pollen and nectar 
of Lupinus species), which was fed to larvae by workers, produced fewer and smaller males (Arnold et al., 2014). $p$-Coumaric acid, a phenolic found in pollen, differentially regulates genes involved in caste determination and influences the development fate of female larvae in A. mellifera (Mao et al., 2015).

Exposure to field realistic levels of in-hive pesticides, fungicides and miticides negatively impacts brood survival and development. Larvae reared in comb containing pesticide residues demonstrated delayed development and increased mortality (Berry et al., 2013; Wu et al., 2011), as well as reduced rates of capping, pupation and eclosion (Yang et al., 2007). Chronic exposure of larvae to dietary pesticides at sublethal levels reduced survival rates (Zhu et al., 2014) as well as causing impaired learning and memory in the ensuing adults (Yang et al., 2007). On a molecular level, changes in gene expression with pesticide exposure were variable but generally minor when a targeted gene approach was used: most notable was higher expression of prophenoloxidase-activating enzyme, an enzyme involved in humoral immunity, and lower expression of a hexameric larval storage protein involved in larval development (Gregorc et al., 2012). A study that explored genome-wide changes in gene expression with pesticide exposure in larvae reported differential expression of 300 transcripts (Derecka et al., 2013): notably, a cluster of genes encoding detoxifying enzymes was overexpressed while expression of genes involved in energy metabolism was reduced. Lipid metabolism was also altered, with lipid profiles indicating effects not only on lipids involved in energy metabolism, but structural lipids as well ( Derecka et al., 2013).

This finding of up-regulation of detoxification genes in combination with down-regulation of genes involved in energy metabolism in larvae exposed to pesticides is surprising. Since it is widely assumed that metabolic detoxification mechanisms in insects are energetically expensive (Berenbaum and Zangerl, 1994; Cresswell et al., 1992; Guedes et al., 2006; Kliot and Ghanim, 2012): however, the absence of evidence for costs has also been reported (Castañeda et al., 2009; Kliot and Ghanim, 2012). Previously, it has been demonstrated that dietary nicotine had no significant adverse effects on lipid and protein reserves in honey bee larvae (Human et al., 2014), suggesting negligible energetic or metabolic costs associated with the observed nicotine tolerance. However, in adult bees nicotine tolerance is associated with oxidative detoxification coupled with an increase in energy metabolism (Du Rand et al., 2015). It is possible that nicotine exposure imposes an energetic demand on larvae and that 
the larvae compensate by down-regulating specific functions which are not necessarily reflected by changes in body mass or body composition.

Nicotine is a highly toxic alkaloid found primarily in the plant family Solanaceae, including tomato, potato, green pepper and tobacco. It is a broadly effective defence against herbivores, with a mode of action resembling that of synthetic neonicotinoids; and is used as a nonsynthetic insecticide in the form of tobacco tea in organic farming methods (Isman, 2006). Nicotine mimics acetylcholine at the neuromuscular junction in mammals, causing twitching, convulsions and even death (Steppuhn et al., 2004; Tomizawa and Casida, 2003). In susceptible insects, the same mode of action is observed in the ganglia of the central nervous system (Tomizawa and Casida, 2003). Only a few insect species such as Myzus persicae (susceptible strains $\mathrm{LC}_{50}<30$ ppm; resistant strains $\mathrm{LC}_{50}>200 \mathrm{ppm}$ ), Bemisia tabaci (resistant strains $\mathrm{LC}_{50}=2000-10000$ ppm) and Manduca sexta are known to tolerate nicotine in their diet (Bass et al., 2013; Kliot et al., 2014; Snyder et al., 1994).

In the present study, we use an integrated mass spectrometry-based proteomic and metabolomic approach to address the question of whether and how honey bee larvae respond to a dietary alkaloid, using nicotine as model compound. The pyridine alkaloid nicotine occurs naturally in the Solanaceae such as tobacco, tomato, potato and green pepper. It is a broadly effective plant defence metabolite against herbivores that binds to the nicotinic acetylcholine receptors at neuromuscular junctions (Tomizawa and Casida, 2003; Steppuhn et al., 2004); and is used as a nonsynthetic insecticide in the form of tobacco tea in organic farming methods (Isman, 2006). In Nicotiana species, leaves contain up to $2000 \mathrm{ppm}$ nicotine while the levels in pollen and nectar are $23 \mathrm{ppm}$ and 0.1-5 ppm, respectively (Adler et al., 2012; Detzel and Wink, 1993; Tadmor-Melamed et al., 2004). We also explored the metabolic fate of the ingested alkaloid in order to shed more light on the detoxification ability of larvae. While genome-wide measurements of mRNA expression levels have undoubtedly revealed important cell-specific processes, there is often only a weak correlation between RNA levels and the abundance of the corresponding proteins (Vogel and Marcotte, 2012). Protein profiles provide indirect insight into the regulation of metabolic flux, while the metabolite profiles provide direct knowledge of relative metabolite concentrations reflecting the metabolic or physiological state. This study is also noteworthy for identifying detoxification processes in healthy honey bee larvae sampled from colonies historically free from routine in-hive preventative treatment for Varroa 
destructor and other diseases. The described data set is free from the confounding effects of miticide and disease treatment and establishes a reference point for normal detoxification processes in studies investigating the synergistic effects of pesticides, disease and malnutrition on honey bee larvae.

\section{Materials and Methods}

\subsection{In vitro larval rearing}

Frames with open brood were collected from strong, queen right Apis mellifera scutellata colonies maintained at the University of Pretoria apiary (Pretoria, South Africa) during late summer (January - April 2013). Two day old worker honey bee larvae were grafted onto larval food in 48-well microtiter plates (Thermo Fisher Scientific, Rochester, New York), using the protocol from Aupinel et al. (2005) and Crailsheim et al. (2013). The grafted larvae (Fig. 1) were kept in an incubator (Humidity chamber HCP108, Memmert GmbH \& Co. KG; Germany) at $34 \pm 1{ }^{\circ} \mathrm{C}$ and $95 \%$ relative humidity in darkness, simulating conditions within the hive. They were removed from the incubator once a day for feeding. Larvae were randomly assigned to plates and the plates were randomly assigned to the experimental or control groups. Each group contained at least 60 larvae. Mortality was recorded on a daily basis. Survival and body mass data were collected from nine colonies in total. Kaplan-Meier and Log Rank (Mantel-Cox) survival analyses were performed to test for differences in survival between the control and nicotine diets. Survival were reported as percentage overall survival. Body mass was compared between the control and nicotine diets using One-way ANOVA. The alpha level was set to 0.05 for all analyses and the data were tested for normality.

\subsection{Larval diets and feeding}

Three standard diets (A, B and C) were used for the in vitro rearing of larvae (Aupinel et al., 2005; Crailsheim et al., 2013). All diets contained 50\% (w/w) fresh royal jelly (Stakich Inc., USA), glucose and fructose (6\%, 7.5\% and $9 \%$ of each in diets A, B and C), and yeast extract $(1 \%, 1.5 \%$ and $2 \%$ in diets $\mathrm{A}, \mathrm{B}$ and $\mathrm{C})$. The nicotine containing diets were prepared by adding nicotine (Sigma-Aldrich, Louis, MO, USA) at a concentration of $300 \mu \mathrm{M}$ (50 ppm) to the standard diets. The concentration of $50 \mathrm{ppm}$ nicotine was selected as the highest 




Fig 1. Effect of 50 ppm dietary nicoitne on larval survial and mass. (A) Effect of 50 ppm nicotine on larval survival after $72 \mathrm{~h}$ chronic exposure. Survival was not significantly affected by 50 ppm nicotine $(\chi 2=3.99 ; \mathrm{df}=1)$. Overall survival was high: $90 \%(\mathrm{n}=500)$ on the nicotine diet and $87 \%(\mathrm{n}=500)$ on the control diet. Data are presented as means \pm SE. (B) Two to three day old honey bee larvae in larval food in a 48-well microtiter plate. (C) Effect of $50 \mathrm{ppm}$ nicotine on body mass $(\mathrm{mg})$ after $72 \mathrm{~h}$ chronic exposure. Body mass was not significantly affected by nicotine (One-way ANOVA, $p$-value $>0.05 ; n=100$ ). Data are presented as means $\pm \mathrm{SE}$. 
concentration of nicotine fed to caged bees with no significant adverse effects (Köhler et al., 2012) and it is also well below the LC 50 of nicotine for honey bees of $2000 \mathrm{ppm}$ (Detzel and Wink, 1993). All larvae received the standard larval diet (A) without nicotine for the first 24 $\mathrm{h}$ after grafting and were thereafter fed on a daily basis with fixed amounts of pre-warmed control or nicotine-containing diets; diet A on day 1 and 2 (10 $\mu 1$ per larva), diet B on day 3 $(20 \mu \mathrm{l})$ and diet $\mathrm{C}$ on day $4(30 \mu \mathrm{l})$. On day 5 the larvae were weighed, rinsed three times with double distilled water to remove excess larval diet, and killed by freezing before storage at $-80{ }^{\circ} \mathrm{C}$ for further analysis.

\subsection{Metabolomic analysis}

Metabolomic profiling analysis was carried out in collaboration with Metabolon Inc. (Durham, NC, USA) as described by Evans et al. (2009). Metabolite profiles were determined in three control and three treatment groups from each of six A.m. scutellata colonies $(n=6)$ with each sample consisting of 50 homogenised larvae. Non-targeted metabolic profiling was performed using three independent platforms: ultrahigh performance liquid chromatography/tandem mass spectrometry optimized for acidic species or for basic species; and gas chromatography/mass spectrometry. Sample preparation, mass spectrometry and data analysis were carried out as described by Du Rand et al. (2015). An extended description of the materials and methods can be found in the Supplementary Materials and Methods.

\subsection{Proteomic analysis}

Protein profiles were determined in three control and three treatment groups from each of three A. m. scutellata colonies ( $\mathrm{n}=3$ ), using label-free, mass spectrometry-based proteomic profiling. Protein extractions were performed as described by Du Rand et al. (2015), using 15 larvae in $1 \mathrm{ml}$ of lysis buffer per sample. The preparative 1D-gel electrophoresis and in gel trypsin digestion, mass spectrometry analysis and data analysis were carried out as described by Du Rand et al. (2015). An extended description of the materials and methods can be found in the Supplementary Materials and Methods.

\subsection{Targeted UPLC-MS/MS metabolite identification and quantification}

Freeze-dried larvae samples (50 larvae per sample) from control and treatment groups from each of six A.m. scutellata colonies (n=6) were reconstituted in $500 \mu 1$ of $50 \%$ methanol and 
centrifuged at $12000 \mathrm{x} \mathrm{g}$ for $10 \mathrm{~min}$. The supernatant was collected and filtered through 0.2 $\mu \mathrm{m}$ syringe filters. Analyses were performed on a Waters ${ }^{\circledR}$ ACQUITY UPLC ${ }^{\text {TM }}$ system (Milford, MA, USA) coupled to a Waters ${ }^{\circledR} \mathrm{Xevo}^{\mathrm{TM}}$ TQ tandem quadrupole mass spectrometer (Milford, MA, USA) with MassLynx ${ }^{\mathrm{TM}}$ software. Reverse phase chromatographic separations were carried out on an ACQUITY UPLC ${ }^{\text {TM }}$ HSS T3 column (2.1 x $150 \mathrm{~mm}, 1.8 \mu \mathrm{m})$ obtained from Waters (Milford, MA, USA). The column temperature was maintained at $50{ }^{\circ} \mathrm{C}$ and the flow rate was set to $0.35 \mathrm{ml} / \mathrm{min}$. Mobile phase A consisted of $10 \mathrm{mM}$ ammonium acetate (adjusted to $\mathrm{pH} 3$ with acetic acid) and mobile phase $\mathrm{B}$ consisted of $10 \mathrm{mM}$ ammonium acetate (adjusted to $\mathrm{pH} 3$ with acetic acid) in acetonitrile (25:475; v:v). The following gradient was used: $0-0.5 \mathrm{~min}, 5 \% \mathrm{~B} ; 0.5-8 \mathrm{~min}, 5-60 \% \mathrm{~B} ; 8$ - 12.9 min, 60 - 100\% B; 12.9 - 13 min, 100 - 5\% B; 13 - 15 min, 5\% B. The injection volume was $2 \mu$ l. The mass spectrometer was operated in electrospray positive mode using multiple reaction monitoring (MRM) data acquisition. The following electrospray ionisation (ESI) conditions were applied: capillary voltage $3.53 \mathrm{kV}$; desolvation temperature $400{ }^{\circ} \mathrm{C}$; desolvation gas (nitrogen) $788 \mathrm{~L} / \mathrm{h}$; cone gas (nitrogen) $51 \mathrm{~L} / \mathrm{h}$; and collision gas flow rate 0.2 $\mathrm{mL} / \mathrm{min}$. Analyte-specific cone voltages, collision energies and MRM transitions are provided in Supplementary Table 4.

\section{Results and Discussion}

\subsection{A. mellifera larvae tolerate high levels of nicotine}

Adult honey bees can tolerate dietary nicotine at levels that are lethal to most insects (Köhler et al., 2012; Singaravelan et al., 2005), yet a study using nucleus hives suggested that larvae are sensitive to nicotine concentrations above 5 ppm (Singaravelan et al., 2006). Using in vitro larval rearing we demonstrated that higher nicotine levels $(50 \mathrm{ppm})$ do not affect larval survival significantly $\left(\chi^{2}=3.99 ; \mathrm{df}=1 ; \mathrm{n}=500\right.$; Fig. 1$)$ confirming the results of Human et al. (2014). Overall larval survival on both the control and nicotine diets was high (Fig. 1).

Chronic ingestion of nicotine for $72 \mathrm{~h}$ also had no significant effect on larval body mass $(F=$ $0.970 ;$ df = 1; n=100; Fig. 1). 
Table 1. Significantly up- or down-regulated metabolites in honey bee larvae after three days of nicotine exposure (Welch's two-sample Student's t-Tests p-value $<0.05$; False discovery rate q-value $<0.1$ ).

\begin{tabular}{|l|c|c|l|}
\hline Metabolite name & Fold change & p-value & Biological process \\
\hline \multicolumn{4}{|c|}{ Up $\uparrow$} \\
\hline Nicotine & 1.29 & 0.0573 & Secondary metabolite \\
\hline Cotinine & 2.11 & 0.0087 & Nicotine catabolite \\
\hline Cotinine N-oxide & 10.75 & 0.0000 & Nicotine catabolite \\
\hline Phenylacetate & 1.60 & 0.2707 & Phe, Tyr metabolism \\
\hline Sedoheptulose-7-phosphate & 1.51 & 0.0137 & Carbohydrate metabolism \\
\hline 1,2-dipalmitoylglycerol & 1.34 & 0.0058 & Lipid metabolism (diacylglycerol) \\
\hline Fucosterol & 1.13 & 0.0187 & Lipid metabolism (sterol/steroid) \\
\hline Orotate & 1.24 & 0.0212 & Pyrimidine metabolism \\
\hline & & Down $\downarrow$ & \\
\hline Adenylosuccinate & 0.61 & 0.0391 & Purine metabolism \\
\hline N-acetyl leucine & 0.87 & 0.1033 & Val, Leu, Ile metabolism \\
\hline N-acetyl isoleucine & 0.77 & 0.0291 & Val, Leu, Ile metabolism \\
\hline Prolylisoleucine & 0.72 & 0.0226 & Dipeptides \\
\hline Arginylisoleucine & 0.74 & 0.0683 & Dipeptides \\
\hline Arginylleucine & 0.72 & 0.0007 & Dipeptides \\
\hline Histidylleucine & 0.74 & 0.0335 & Dipeptides \\
\hline 1-octadecanol & 0.65 & 0.0176 & Lipid metabolism (fatty alcohol, long chain) \\
\hline Pyridoxate & 0.90 & 0.0536 & Cofactors \& vitamins (pyridoxal metabolism) \\
\hline
\end{tabular}


Table 2. Summary of differentially expressed proteins in larvae after three days of nicotine exposure (ANOVA t-Test, p-value<0.05; False discovery rate q-value $<0.01$ ).

\begin{tabular}{|c|c|c|}
\hline \multirow{2}{*}{ Biological process/Function } & \multicolumn{2}{|c|}{ Number of proteins } \\
\hline & $\mathbf{U p} \uparrow$ & Down \\
\hline Energy metabolism (oxidative phosphorylation) & 6 & 3 \\
\hline Carbohydrate metabolism and transport & 10 & 3 \\
\hline Lipid metabolism and transport & 3 & 4 \\
\hline Amino acid metabolism and transport & 4 & 3 \\
\hline Glutathione metabolism & - & 1 \\
\hline Detoxification and stress response & 14 & 4 \\
\hline Transcription & 13 & 2 \\
\hline Translation & 15 & 9 \\
\hline Protein processing, modifications, folding and transport & 17 & 3 \\
\hline Nucleosome assembly & 2 & - \\
\hline Mitochondrial biogenesis & 1 & - \\
\hline Larval growth and development & 5 & - \\
\hline Cuticle and Chitin metabolism & 6 & - \\
\hline Signal transduction & 6 & 1 \\
\hline Cytoskeleton & 1 & 1 \\
\hline Cofactor and vitamin metabolism & 1 & - \\
\hline Olfaction & 1 & - \\
\hline Unknown & 30 & 10 \\
\hline TOTAL & 135 & 44 \\
\hline
\end{tabular}




\subsection{A. mellifera larvae metabolise nicotine exploiting oxidative detoxification strategies}

To address the question of whether and how larvae respond to a dietary toxin, the protein and metabolite profiles of in vitro reared larvae continuously exposed to nicotine for $72 \mathrm{~h}$ were determined using mass spectrometry based proteomic and metabolomic analysis. A total of 414 metabolites was identified of which the levels of only 17 compounds were significantly altered (Table 1). Global protein profiles revealed that of the total 1470 proteins identified, 135 were significantly up-regulated and 44 were down-regulated in the nicotine exposed samples (Table 2; Entire lists of the differentially expressed proteins, including accession numbers, fold change and predicted functions can be found in Supplementary Tables 1 and 2).

Nicotine was detected only in the metabolite profiles of nicotine exposed larvae, as expected, along with two known oxidation products of nicotine, cotinine and cotinine N-oxide (Hukkanen et al., 2005; Snyder et al., 1994). Cotinine and cotinine N-oxide are the products of P450-mediated 5'oxidation of nicotine (Hukkanen et al., 2005; Snyder et al., 1994). This provides the first evidence that larvae are capable of metabolising nicotine. To confirm this, the metabolic fate of nicotine in larvae that consumed $50 \mathrm{ppm}$ nicotine diets for $72 \mathrm{~h}$ was examined using a targeted UPLC-MS/MS approach. Nicotine metabolism was extensive: the end product of 2'C-oxidation of nicotine, 4-hydroxy-4-(3-pyridyl) butanoic acid, was present at levels 60 times higher than nicotine and 16 times higher than any other metabolite detected in larvae reared on the nicotine diet (Fig. 2, Supplementary Table 3). Although intermediates of the 2'C-oxidation catabolic pathway of nicotine have been reported in Myzus persicae (Bass et al., 2013), 4-hydroxy-4-(3-pyridyl) butanoic acid has not been reported in any other insect before. Apart from 4-hydroxy-4-(3-pyridyl) butanoic acid, which represented 91\% of the total nicotine and nicotine-derived compounds detected in the larvae, lower levels of cotinine $(5.4 \%)$ and smaller amounts of cotinine N-oxide (2.1\%) were also present. (Du Rand et al., 2017) demonstrated that the formation of 4-hydroxy-4-(3-pyridyl) butanoic acid is quantitatively the most significant pathway of nicotine metabolism in adult honey bees, constituting the basis for the high nicotine tolerance in adults. The nicotine catabolite profile in nicotine reared larvae emulates the catabolite profile found in adults that ingested nicotine (Du Rand et al., 2017) and provides conclusive evidence that honey bee larvae are capable of effectively metabolising dietary toxins. 


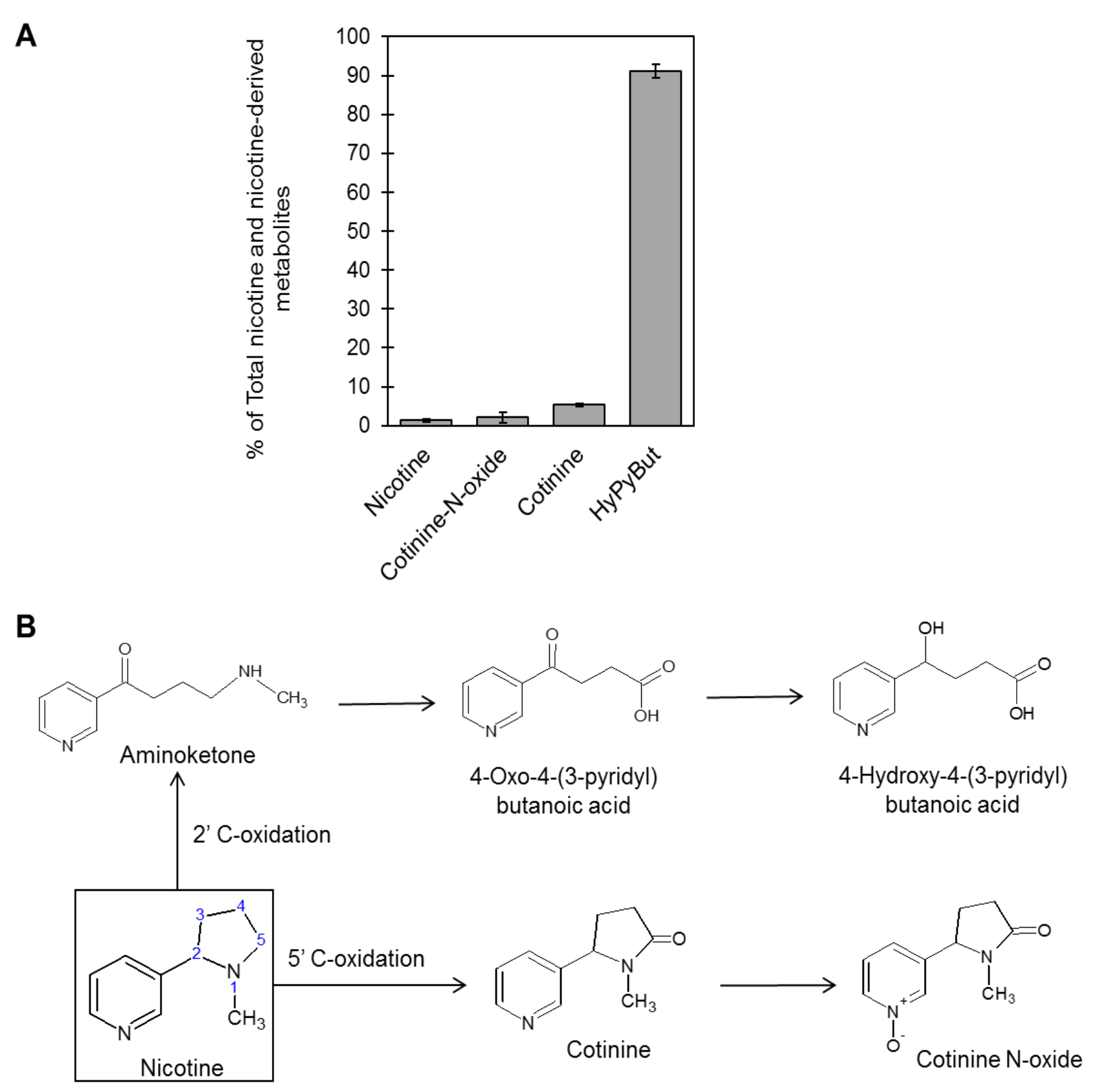

Fig. 2. The metabolic fate of nicotine in A. mellifera larvae. (A) Nicotine and its metabolites detected in larvae after consuming a $50 \mathrm{ppm}$ nicotine diet for $72 \mathrm{~h}$. Data represent the mean of six experiments $\pm \mathrm{SE}$ and are expressed as percentage of the total nicotine and nicotine metabolites detected $(n=6 ; 50$ larvae per sample). (B) Conversion of nicotine to its major metabolites in larvae. In humans up to $75 \%$ of nicotine is oxidized to cotinine through the 5'C-oxidation pathway. In honey bees and nicotine-resistant aphids, the 2'C-oxidation of nicotine is the main catabolic pathway. Diagram adapted from (Hukkanen et al., 2005).. 
Other nicotine tolerant insects also employ oxidative detoxification to cope with high levels of dietary nicotine. The tobacco specialist caterpillar Manduca sexta and other Sphingidae metabolise nicotine to cotinine and cotinine $\mathrm{N}$-oxide via a P450-mediated pathway (Kumar et al., 2014; Snyder et al., 1994; Wink and Theile, 2002). In nicotine-resistant lineages of the peach potato aphid M. persicae, CYP6CY3 is responsible for the oxidation of nicotine to pharmacologically less active metabolites, aminoketone and cotinine (Bass et al., 2013). Likewise, in the tobacco whitefly Bemisia tabaci the primary mechanism of nicotine resistance is enhanced detoxification due to overexpression of the P450 CYP6CM1(Kliot et al., 2014). Together, these observations suggest that that the oxidation of nicotine by bee larvae constitutes true detoxification and that the catabolism of nicotine is most likely P450mediated.

Indeed, two P450s, CYP6BD1 (GB19306) and CYP9Q1 (GB19820), were significantly upregulated in response to nicotine consumption in larvae. Members of the CYP6 and CYP9 families are associated with environmental response and detoxification functions in insects (Li et al., 2007). CYP9Q1 mediates acaricide and pyrethroid detoxification and is also able to efficiently metabolise the nectar and pollen flavonol, quercetin in honey bees (Mao et al., 2011). CYP6BD1 in honey bees has not been functionally characterised yet, but its overexpression has been associated with exposure to $p$-coumaric acid, a monomer of sporopollenin which is the principal constituent of pollen cell walls (Mao et al., 2013). In the larvae of specialist papilionid lepidopterans (swallowtails), CYP6B proteins are associated with the efficient detoxification of xanthotoxin and other furanocoumarins ( $\mathrm{Li}$ et al., 2004), while in generalist noctuid lepidopteran larvae (owlet moth), the CYP6B family is capable of metabolising a broad range of plant secondary metabolites such as quercetin, flavone and chlorogenic acid, as well as pesticides such as diazinon, cypermethrin and Aldrin (Li et al., 2004). The overexpression of CYP6BD1 and CYP9Q1 after nicotine exposure suggests that these two P450s play a role in nicotine tolerance in honey bee larvae and are likely responsible for the phase I detoxification products of nicotine observed in larvae.

In addition to the two up-regulated P450s, another protein associated with detoxification of plant secondary metabolites in insects was considerably up-regulated after nicotine exposure: LOC727344 (GB43690) resembles the nitrile-specifier protein (NSP) identified in the larvae of Pieris rapae, which enables them to feed on glucosinolate-containing plants (Wittstock et 
al., 2004; Wittstock and Burow, 2007). NSP belongs to a group of insect proteins that have not been functionally characterised but it seems to function as a cofactor to proteins involved in secondary metabolite metabolism (Wittstock et al., 2004; Wittstock and Burow, 2007).

Also up-regulated two-fold was the phase III associated transporter protein, multidrug resistance-associated protein 1 (MRP1; GB53134). Multidrug resistance-associated proteins are a subfamily of the ATP-binding cassette (ABC) superfamily of transmembrane transporters (Leslie, 2001). These proteins actively shuttle toxins across cell membranes to reduce the intracellular toxin and metabolite concentrations. Working in concert with metabolic enzymes, these transporters can mediate a baseline tolerance to a diverse array of toxins including pesticides and plant secondary metabolites in insects (Chahine and O’Donnell, 2009; Dow and Davies, 2006; Hawthorne and Dively, 2011; Labbé et al., 2011). In honey bees, up-regulation of MRP1 is associated with exposure to $p$-coumaric acid, a phenolic acid present in pollen (Mao et al., 2013). Therefore, MRP1 might play a role in the rapid elimination of nicotine and its metabolites from cells and tissues, contributing to nicotine tolerance in honey bee larvae.

\subsection{Nicotine consumption increases energy metabolism in $A$. mellifera larvae}

Resistance to plant and synthetic toxins is associated with fitness costs and in insects metabolic resistance often involves an energy cost (Kliot et al., 2014; Kliot and Ghanim, 2012). Significant overexpression of proteins involved in aerobic energy metabolism was observed in nicotine exposed larvae (Table 2). The oxidative phosphorylation (OXPHOS) pathway was strongly up-regulated with the overexpression of six proteins involved in complexes I, II, IV and F-ATPase (see Fig. 3, Supplementary Table 1). The catalytic TCA cycle, which supplies the NADH required by the electron transport chain to produce ATP, was also substantially up-regulated as exemplified by the overexpression of succinate dehydrogenase (GB52753), malic enzyme (Mdh; GB49967) and one of the rate limiting enzymes of the TCA cycle, isocitrate dehydrogenase (GB48527). This likely indicates a higher energy demand in larvae subjected to dietary nicotine. In other insects, including Sitophilus zeamais (Guedes et al., 2006) and B. tabaci (Ghanim and Kontsedalov, 2007), resistance to plant toxins and pesticides has also been associated with the increased expression of genes and proteins involved with OXPHOS and energy metabolism. 


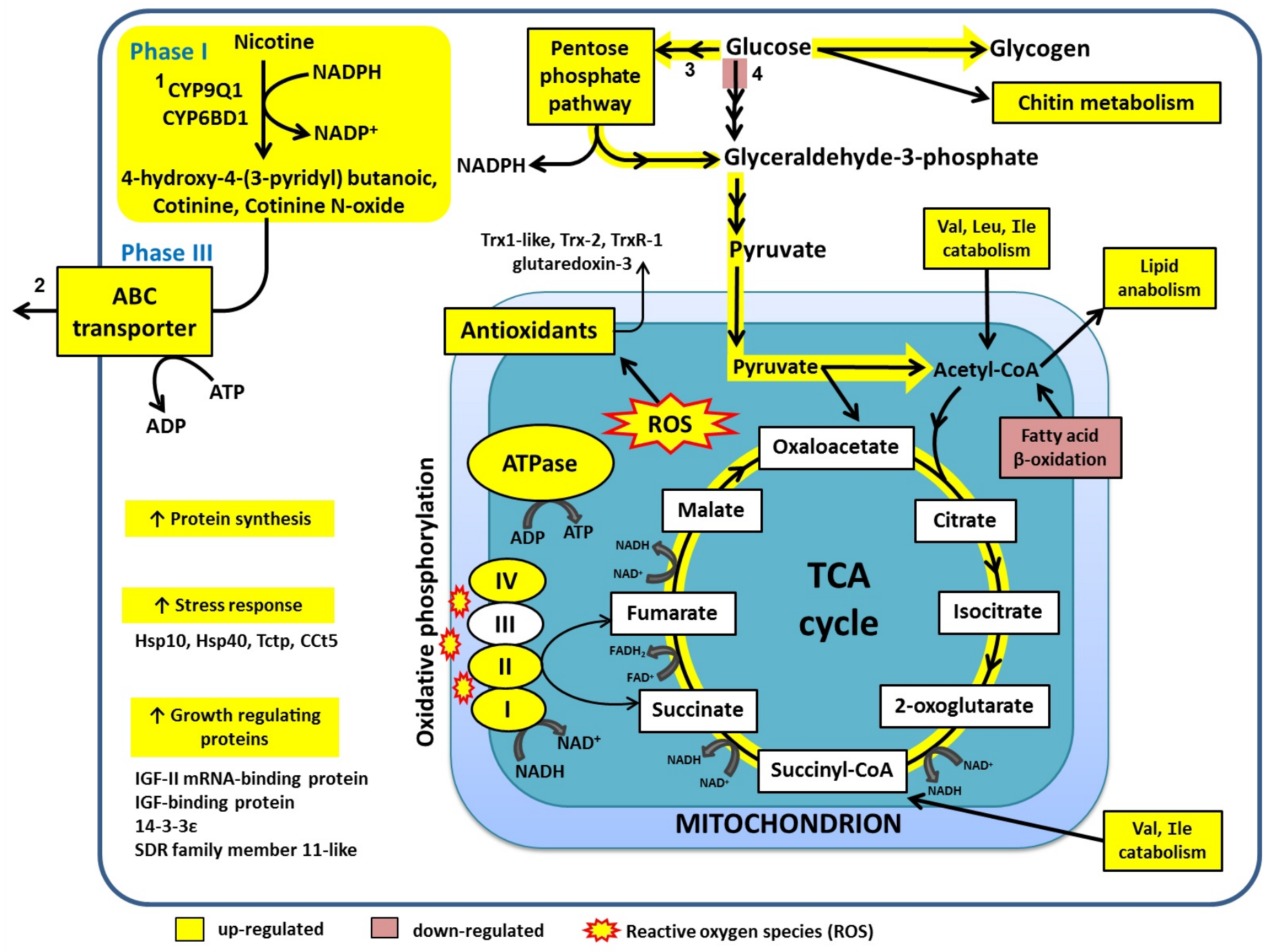

Fig. 3. Scheme summarizing the proposed mechanisms underlying the response of honey bee larvae to nicotine exposure. Nicotine is oxidised to less toxic metabolites, cotinine and cotinine $\mathrm{N}$-oxide by the overexpressed phase I detoxification enzymes CYP6BD1 and CYP9Q1 (1) followed by the elimination (phase III) from the cells by an ABC transporter (2). The up-regulation of enzymes involved in ATP synthesis, stage two of glycolysis and the TCA cycle suggests increased energy production to support or drive the detoxification processes. The first and rate-limiting step of the pentose phosphate pathway (3) is up-regulated while the first step of glycolysis (4) is down-regulated, increasing the flux through the pentose phosphate pathway to meet the higher demand for NADPH (NADPH is required for P450 functioning, TrxR-1 functioning and the reductive biosynthesis of fatty acids and steroids). Increased energy production leads to increased ROS production which induces enhanced expression of enzymatic antioxidants as part of the stress response to protect against oxidative damage. Other elements of the cellular stress response (Hsp 40, Hsp 10, Tctp, Cct5 are also substantially up-regulated to promote stress tolerance 
The observed increased expression of several proteins involved in carbohydrate metabolism and transport adds support to the idea of increased oxidative metabolism. The overexpression of 6-phosphogluconate dehydrogenase (Pgd; GB52074; the enzyme that catalyses the first and rate limiting step of the pentose phosphate pathway and controls the flux of glucose through the pathway) in conjunction with the down-regulation of hexokinase (GB47079; the enzyme catalysing the first step in glycolysis) not only reflects the up-regulation of the pentose phosphate pathway but also the diversion of glucose to this pathway (depicted in Fig. 3). This observation was confirmed by the metabolomic profiling which revealed increased levels of sedoheptulose-7-phosphate, an intermediate in the pentose phosphate pathway. The pentose phosphate pathway is the alternative route for the metabolism of glucose and in addition to supplying ribose-5-phosphate for nucleotide biosynthesis, it serves as a major source of reducing power by producing NADPH required for P450 functioning and maintaining the redox state of cells (Voet et al., 2013). Ribose-5-phosphate molecules can be converted to the glycolytic intermediates fructose-6-phosphate and glyceraldehyde-3phosphate which re-enter glycolysis to be further processed aerobically for efficient production of energy. The up-regulation of the second stage of glycolysis is exemplified by the overexpression of phosphoglycerate mutase (GB46214) and the rate limiting enzyme pyruvate dehydrogenase (GB43905; pyruvate $\rightarrow$ acetyl CoA) which catalyses the last reaction of glycolysis. The differential regulation of these enzymes involved in glycolysis and the pentose phosphate pathway not only supports the notion of increased energy demand, but also points to an increased demand for NADPH required for detoxification processes as well as regulating the redox state of cells.

\subsection{Effect on larval growth and development associated processes}

During the larval stage, honey bees and other holometabolous insects accumulate energy reserves to support development of adult tissues during metamorphosis (Arrese and Soulages, 2010; Feng et al., 2014). Carbohydrates are stored as glycogen and lipids as triglyceride. Interestingly, nicotine exposure in larvae seems to stimulate an increase in the synthesis of energy stores: glycogen synthase (GB54391), the rate limiting enzyme in glycogen synthesis, was significantly up-regulated (Supplementary Table 1; Fig. 3). Furthermore, proteins involved in lipid biosynthesis and storage were also up-regulated including fatty acyl-CoA reductase 1-like (GB52308), elongation of very long chain fatty acids protein (GB51247) and a lipid storage droplet surface binding protein (GB47140; Lsd-1;3-fold). At the same time 
fatty acid $\beta$-oxidation was down-regulated as exemplified by the down-regulation of short/branched chain specific acyl-CoA dehydrogenase (GB50239), probable medium-chain specific acyl-CoA dehydrogenase (GB42141) and aldehyde dehydrogenase family 7 member A1 (GB55701). An increase in lipid biosynthesis was confirmed by variation in the abundance of metabolites such as 1,2-dipalmitoylglycerol, 1-octadecanol and fucosterol. Increased lipid biosynthesis metabolism would lead to an increased demand for NADPH, which would in part explain the observed increased flux through the pentose phosphate pathway described earlier.

In addition to energy storage, increased lipid metabolism might also indicate an increased requirement for building blocks for cell membranes, steroid hormones, etc. However, the overexpression of proteins involved in the Insulin/Insulin-like growth factor signalling pathway (IIS) indicates that nutrient storage is being up-regulated: IGF-II mRNA-binding protein (GB52056) and IGF-binding protein (GB49397) were up-regulated 2-fold. IIS promotes carbohydrate storage by phosphorylating glycogen, amongst other functions (Chapman, 2013). Hexamerin 70c (GB51696), another nutrient storage protein, was also present at significantly higher levels in nicotine exposed larvae. Hexamerins are synthesized mainly by the fat body during larval development and primarily function as storage proteins that serve as a source of amino acids during metamorphosis (Martins et al., 2010). An increase in the accumulation of energy and other nutrient storage proteins suggests that nicotine influenced larval growth positively.

IIS also influence growth directly by stimulating cell proliferation and protein synthesis. Nicotine exposed larvae exhibited increased levels of a downstream target of IIS, 14-3-3e (GB15582). 14-3-3 $\varepsilon$ serves as a central modulator of the activity of the transcription factor FOXO thereby regulating growth, apoptosis and longevity (Nielsen et al., 2008). Increased IIS signalling leads to the inactivation of FOXO by $14-3-3 \varepsilon$ which results in increased cell proliferation (Nielsen et al., 2008). Strengthening the argument for increased cell proliferation is the particularly striking 7-fold and 9-fold up-regulation of the histone proteins Histone H4 (GB47407) and Histone H2B (XP_001120889.1), respectively. Histone gene expression is cell cycle regulated and coupled to DNA replication during the $S$ phase (Rattray and Müller, 2012). 
Other proteins involved in regulating growth and development in honey bees such as SDR family member 11 (GB40770) (Erban et al., 2014; Feng et al., 2014) was also significantly overexpressed. SDRs play a pivotal role in ecdysteroid biosynthesis (Niwa et al., 2010) and in A. mellifera specifically, they have been reported to be a target of the ecdysone response during caste development (Guidugli et al., 2004).

Chitin metabolism, a process tightly coupled to larval development and growth, was also upregulated. Proteins involved in chitin metabolism were overexpressed in larvae exposed to dietary nicotine; this included the 3-fold up-regulation of trehalase (GB55489). Trehalase hydrolyses trehalose to generate glucose that can be further processed through glycolysis or the pentose phosphate pathway. Trehalase also catalyses the first step in chitin biosynthesis (Chen et al., 2010; Liu et al., 2013). Other important proteins involved in chitin biosynthesis were also up-regulated, including SP23 (GB50482), NADH-cytochrome b5 reductase 2-like isoform 1 (GB48597) and UDP-N-acetylglucosamine pyrophorylase (GB44897; mmy).

Overexpression of these proteins in conjunction with increased levels of cuticular proteins such as cuticular protein CPF1 precursor (GB13601), cuticular protein precursor (GB42597) and flexible cuticle protein 12 (NP_001257753.1) strongly suggest that cuticle formation is up-regulated. This is supported by the overexpression of chemosensory protein 3 (CSP3, also known as ASP3c; GB52324). Although proposed to be an antenna brood pheromone-binding protein (Briand et al., 2002), the expression patterns of CSP3 in larval and pupal development stages suggest CSP3 may play a role in cuticle maturation (Dani et al., 2010; Forêt et al., 2007).

The overexpression of the chitin anabolic enzyme UDP-N-acetylglucosamine pyrophorylase is a strong indication that growth and development pathways are up-regulated in nicotine exposed larvae. This multifunctional protein not only plays a key role in chitin biosynthesis, but was also demonstrated to be essential in moulting during development, as well as playing a crucial role in the morphogenesis of the central nervous system by ensuring normal development of the midline glia and axon fasciculation (Araújo et al., 2005; Schimmelpfeng et al., 2006).

Taken together, the data suggest that dietary nicotine promotes the growth of honey bee larvae through modulating signalling pathways and central modulators of nutrient storage, 
chitin metabolism and cell proliferation, processes tightly linked to larval growth and development. This is not a singularity, as nicotine resistant-strains of $M$. persicae and $B$. tabaci also demonstrated increased growth on nicotine containing diets (Kliot et al., 2014; Ramsey et al., 2014). While nicotine is a possible source of nitrogen and could lead to increased growth, this is an unlikely hypothesis as the artificial rearing diets consisted of $50 \%$ $(\mathrm{w} / \mathrm{w})$ royal jelly, ensuring a rich source of amino acids. Although our results suggest $50 \mathrm{ppm}$ nicotine has a positive effect on growth, no significant differences in development time, body weight or composition were observed at the prepupal stage after larvae were reared on a diet containing 5 ppm nicotine (Human et al., 2014). The effects of nicotine may be dosedependent, with only higher levels of nicotine ( $>5 \mathrm{ppm})$ significantly affecting larval growth. The dose-dependent effects of dietary nicotine have previously been demonstrated in nicotine-resistant lineages of B. tabaci and M. persicae (Kliot et al., 2014; Ramsey et al., 2014). It is worth noting, however, that it is plausible that some of the observed changes in growth related processes such chitin metabolism and cell proliferation could also be related to the action of this natural insecticide on the insect nervous system and the subsequent downstream effects. Additional studies investigating the proteomic response of different larval stages to $50 \mathrm{ppm}$ nicotine as well as the effects on development time, body mass, and body composition are required to confirm or refute the hypothesis that nicotine enhances larval growth.

\subsection{Altered protein and amino acid metabolism}

Many of the proteins that were overexpressed after nicotine exposure were related to protein metabolism (Table 2 and Supplementary Table 1). These included several ribosomal proteins, likely as a consequence of elevation of the protein synthesis machinery, as well as proteins involved in folding, modification, sorting, transport and degradation of proteins. The upregulation of protein metabolism is most likely related to an increased demand for the proteins involved in the observed increased oxidative metabolism, nicotine detoxification, and the putative up-regulation of larval growth and development as suggested by our data. Nicotine exposed larvae also exhibited increased expression of isovaleryl-CoA dehydrogenase (GB51088) and succinyl-CoA:3 ketoacid coenzyme A transferase (GB41843). These enzymes are indicative of increased catabolism of the branched chain amino acids leucine, isoleucine and valine. This observation was confirmed by the metabolomic profiling which revealed increased levels of $\mathrm{N}$-acetyl leucine and $\mathrm{N}$-acetyl 
isoleucine, intermediates in the branched chain amino acid catabolic pathway. Branched chain amino acids can contribute to energy metabolism as an energy source, provide building blocks for as fatty acid biosynthesis, and can also replenish or expand the pool of TCA cycle intermediates used as precursors in biosynthetic pathways (Shimomura et al., 2004). Nicotine exposed larvae also exhibited increased expression of protein henna-like isoform 2 (phenylalanine-4-hydroxylase; GB48022), the enzyme catalysing the conversion of phenylalanine to tyrosine and the rate-limiting step in phenylalanine metabolism. This observation was confirmed by the metabolomic profiling which revealed fluctuating levels of phenylacetate, an intermediate in phenylalanine metabolism. The reason for the altered homeostasis of these amino acids after dietary nicotine exposure requires further investigation.

\subsection{Stress response}

Reactive oxygen species (ROS) are generated as by-products of aerobic energy metabolism and increased ROS production has also been associated with $\mathrm{p} 450$-mediated detoxification processes (Miwa et al., 2003; Murataliev et al., 2008). Honey bees maintain complex systems of multiple types of antioxidants to regulate intracellular ROS balance and prevent ROSmediated damage (Corona and Robinson, 2006). Several proteins associated with oxidative stress resistance in honey bees and other insects were up-regulated in the nicotine exposed larvae. ATOX1-like (GB55561), a protein connected to defence against ROS in insects (Kim et al., 2006), was up-regulated 2-fold. We also observed a 3-fold increase in the levels of thioredoxin reductase 1 (TrxR-1; GB40718) and thioredoxin 2 (Trx-2; GB48574) and a 2fold increase in levels of both thioredoxin 1-like (Trx1-like; GB48215) and glutaredoxin 3 (GB49471). Trx-2, Trx1-like and glutaredoxin are part of the primary antioxidant response and act directly on ROS molecules. TrxR-1 recycles oxidized thioredoxin back to its reduced state by using electrons from NADPH and oxidized glutaredoxin proteins are regenerated by reduced GSH. In turn, the oxidized GSH (GSSG) is reduced by TrxR in insects (Corona and Robinson, 2006). These proteins have all been reported to be present in A. mellifera larvae during development (Cameron et al., 2013; Feng et al., 2014; Li et al., 2009). In the sister species of A. mellifera, A. cerana, these antioxidant proteins play critical roles in resisting oxidative stress and were shown to be transiently overproduced under stress conditions including pesticide exposure (Lu et al., 2012; Yao et al., 2014, 2013). 
Apart from antioxidant activity, other components of the cellular stress response were also up-regulated. Molecular chaperones, including heat shock proteins (Hsp) ensure the correct folding of proteins and assist in degradation of denatured or aggregated proteins (Voet et al., 2013). The epsilon subunit of t-complex protein 1 (Cct5; GB50652) of the TCP chaperonin family, which is primarily associated with cytoskeletal proteins, tubulins, and actins (Coghlin et al., 2006) was overexpressed in nicotine exposed larvae. In addition, the levels of Hsp 10 (GB54343) increased 2-fold in nicotine exposed larvae as well as a member of the DnaJ family (GB12215). Members of the DnaJ family (also referred to as the Hsp 40 family) are co-chaperones of Hsp 70. Hsp 70 proteins function in routine de novo protein folding under normal conditions. Under stressed conditions they prevent protein aggregation by binding denatured proteins. Hsp 10 functions as a co-chaperone with Hsp 60 to modulate protein folding under both normal and stress conditions. Cct5, Hsp 10 and DnaJ are expressed in $A$. mellifera larvae under unstressed conditions (Erban et al., 2014; Feng et al., 2014; Li et al., 2009). The significant up-regulation of these molecular chaperones in nicotine exposed larvae suggests a role in tolerating increased levels of stress caused either by the putative increase in growth and development or by toxic action of nicotine on the insect central nervous system.

We also observed the up-regulation of the multifunctional protein, translationally-controlled tumor protein homolog isoform 1 (Tctp; GB42809). Among others, Tctp is essential for growth and proliferation (it is an important component of the TOR signalling pathway) and it also plays a role in DNA damage sensing and repair (Hsu et al., 2007; Zhang et al., 2012). The presence of Tctp in growing honey bee larvae suggests a role in growth and proliferation in bees (Erban et al., 2014; Feng et al., 2014) which links with the increased growth and development suggested by the data in this study. However, Tctp may also play a role in DNA damage sensing and repair as part of the oxidative stress response due to the increased aerobic metabolism or the general defence response against nicotine toxicity in honey bee larvae.

\subsection{Concluding remarks}

Oxidative detoxification by $\mathrm{P} 450$ s appears to be the basis for the tolerance that honey bee larvae show towards nicotine. Larvae actively detoxify nicotine to 4-hydroxy-4-(3-pyridyl) butanoic acid, cotinine and cotinine $\mathrm{N}$-oxide, providing conclusive evidence of the ability of honey bee larvae to metabolise dietary toxins. These detoxification processes, complemented 
by oxidative and general stress responses, are associated with an increase in energetic investment (see Fig. 3), closely resembling the nicotine tolerance mechanism reported for newly emerged worker honey bees (Du Rand et al., 2017, 2015). In addition, specific P450s could be linked to the detoxification of the secondary plant metabolite in honey bee larvae: Nicotine exposure in larvae was associated with the overexpression of two P450s, CYP6BD1 and CYP9Q1, that are likely directly involved with the enzymatic detoxification of nicotine. Larvae also exhibited the overexpression of an ABC transporter associated with rapid elimination of toxins from cells. The up-regulation of phase I and phase III detoxification proteins in response to nicotine exposure suggests that larval detoxification mechanisms are inducible. A similar induction of phase I and phase III detoxification proteins was not observed in adult bees (Du Rand et al., 2015) even though the same phase I detoxification products were present in adults and larvae. This suggested that the phase I and phase III detoxification proteins in question were expressed constitutively in adult bees. The inducibility of larval detoxification enzymes might confer an adaptive plasticity on growing larvae that enables them to optimise their fitness in the presence of toxins or alternatively might simply be related to age-specific protein expression patterns.

A notable difference between larval and adult (Du Rand et al., 2015) stress responses to nicotine exposure was also observed. The stress response of larvae to nicotine involved the up-regulation of a larger array of molecular chaperones and antioxidant proteins than the stress response of adults, most probably reflecting age-specific protein expression patterns. Curiously, Hsp 90 was unaffected in larvae, while in adults there was a dramatic 12-fold increase in expression following nicotine exposure (Du Rand et al., 2015). One interpretation is that the dramatic regulation of Hsp 90 in adults points to the adults being more sensitive to nicotine, but there is no toxicology data currently available that directly compares nicotine sensitivity of adults and larvae to support such a hypothesis. The more likely explanation is that it is an age-specific response and that larvae rely more heavily on the abundance of other molecular chaperones that were up-regulated, including Hsp 70 and Hsp 60 associated proteins, to fulfil the same functions as Hsp 90.

Furthermore, nicotine seems to promote larval growth. In agreement with putative enhanced growth, the flux of glucose through the pentose phosphate pathway exhibited a higher degree of regulation than observed for adult bees. This is reflected by the down-regulation of the first 
reaction of glycolysis (hexokinase) and the concomitant up-regulation of the first and rate limiting step of the pentose phosphate pathway (glucose dehydrogenase). Concurrently, the second phase of glycolysis (phosphoglycerate mutase and the rate limiting enzyme pyruvate dehydrogenase) where intermediates produced by the pentose phosphate pathway can enter glycolysis was also up-regulated (see Fig. 3). These changes support increased flux through the pentose phosphate pathway to meet the increased demand for NADPH required for P450 functioning, maintenance of the cellular redox state and biosynthetic pathways involved in growth. The prominence of molecular chaperones in the larval stress response might in part be due to the putative up-regulated growth.

Taken together, the findings provide novel insight into the molecular response mechanisms of developing worker larvae to a naturally occurring dietary toxin, contributing to our understanding of honey bee detoxification biochemistry. Although it has been previously suggested that larvae have the ability to detoxify dietary toxins through enzymatic detoxification mechanisms (Derecka et al., 2013; Gregorc et al., 2012; Mao et al., 2015) much of the information regarding detoxification is assumed, based on evidence from adult worker bees (Johnson et al., 2012, 2006; Mao et al., 2011, 2009). This study provides conclusive evidence that larvae can indeed efficiently metabolise dietary toxins. This suggests that if larvae are more sensitive to a specific dietary toxin than adult bees, diminished detoxification ability is not a contributing factor as generally assumed. Honey bees have been exposed to toxic plant secondary metabolites in their environment throughout their evolutionary history (Johnson, 2015) and are adapted to tolerate and thrive in the presence of these toxic compounds. Characterising the underlying mechanisms that allow honey bees of different development stages to cope with these hazardous plant constituents in their diet brings us closer to the ultimate goal of understanding the capacity of the colony as a superorganism to tolerate and resist toxic compounds, including pesticides, in the environment. A better understanding and knowledge of the limits of pesticide tolerance in honey bees aids in making informed decisions and formulating scientifically supported policies regarding bee conservation.

\section{Acknowledgements}

Kendall Crous is thanked for beekeeping. 
Funding: This work was funded jointly by a grant from the Biotechnology and Biological Sciences Research Council (BBSRC), Natural Environment Research Council (NERC), the Wellcome Trust, Defra, and the Scottish Government under the Insect Pollinators Initiative (BB/I000968/1). We also acknowledge the support of the National Research Foundation of South Africa and the University of Pretoria. 


\section{References}

Adler, L.S., Seifert, M.G., Wink, M., Morse, G.E., 2012. Reliance on pollinators predicts defensive chemistry across tobacco species. Ecol. Lett. 15, 1140-1148.

Araújo, S.J., Aslam, H., Tear, G., Casanova, J., 2005. mummy/cystic encodes an enzyme required for chitin and glycan synthesis, involved in trachea, embryonic cuticle and CNS development - analysis of its role in Drosophila tracheal morphogenesis. Dev. Biol. 288, 179-193.

Arnold, S.E.J., Idrovo, M.E.P., Arias, L.J.L., Belmain, S.R., Stevenson, P.C., 2014. Herbivore defence compounds occur in pollen and reduce bumblebee colony fitness. J. Chem. Ecol. 40, 878-881.

Arrese, E.L., Soulages, J.L., 2010. Insect fat body: energy, metabolism, and regulation. Annu. Rev. Entomol. 55, 207-225.

Aupinel, P., Fortini, D., Dufour, H., Tasei, J., Michaud, B., Odoux, J., Pham-Delegue, M., 2005. Improvement of artificial feeding in a standard in vitro method for rearing Apis mellifera larvae. Bull. Insectology 58, 107-111.

Aupinel, P., Fortini, D., Michaud, B., Marolleau, F., Tasei, J., Odoux, J.-F., 2007. Toxicity of dimethoate and fenoxycarb to honey bee brood (Apis mellifera), using a new in vitro standardized feeding method. Pest Manag. Sci. 63, 1090-1094.

Bass, C., Zimmer, C.T., Riveron, J.M., Wilding, C.S., Wondji, C.S., Kaussmann, M., Field, L.M., Williamson, M.S., Nauen, R., 2013. Gene amplification and microsatellite polymorphism underlie a recent insect host shift. Proc. Natl. Acad. Sci. USA 110, 19460-19465.

Berenbaum, M.R., Zangerl, A.R., 1994. Costs of inducible defense: protein limitation, growth, and detoxification in parsnip webworms. Ecology 75, 2311.

Berry, J.A., Hood, W.M., Pietravalle, S., Delaplane, K.S., 2013. Field-level sublethal effects of approved bee hive chemicals on honey bees (Apis mellifera L). PLoS ONE 8, e76536.

Blacquière, T., Smagghe, G., van Gestel, C.A.M., Mommaerts, V., 2012. Neonicotinoids in bees: a review on concentrations, side-effects and risk assessment. Ecotoxicology 21, 973-992. 
Briand, L., Swasdipan, N., Nespoulous, C., Bézirard, V., Blon, F., Huet, J.-C., Ebert, P., Pernollet, J.-C., 2002. Characterization of a chemosensory protein (ASP3c) from honeybee (Apis mellifera L.) as a brood pheromone carrier: brood pheromone binding by bee chemosensory protein. Eur. J. Biochem. 269, 4586-4596.

Buttstedt, A., Ihling, C.H., Pietzsch, M., Moritz, R.F.A., 2016. Royalactin is not a royal making of a queen. Nature 537, E10-E12.

Cameron, R.C., Duncan, E.J., Dearden, P.K., 2013. Biased gene expression in early honeybee larval development. BMC Genomics 14, 903.

Castañeda, L.E., Figueroa, C.C., Fuentes-Contreras, E., Niemeyer, H.M., Nespolo, R.F., 2009. Energetic costs of detoxification systems in herbivores feeding on chemically defended host plants: a correlational study in the grain aphid, Sitobion avenae. J. Exp. Biol. 212, 1185-1190.

Chahine, S., O’Donnell, M.J., 2009. Physiological and molecular characterization of methotrexate transport by Malpighian tubules of adult Drosophila melanogaster. J. Insect Physiol. 55, 927-935.

Chapman, R.F., 2013. Fat body, in: The Insects: Structure and Function (eds Simpson,S.J., Douglas, A.E.). Cambridge University Press, pp. 132-148.

Chauzat, M., Faucon, J., 2007. Pesticide residues in beeswax samples collected from honey bee colonies (Apis mellifera L.) in France. Pest Manag. Sci. 63, 1100-1106.

Chauzat, M., Faucon, J., Martel, A., Lachaize, J., Cougoule, N., Aubert, M., 2006. A survey of pesticide residues in pollen loads collected by honey bees in France. J. Econ. Entomol. 99, 253-262.

Chauzat, M.-P., Martel, A.-C., Cougoule, N., Porta, P., Lachaize, J., Zeggane, S., Aubert, M., Carpentier, P., Faucon, J.-P., 2011. An assessment of honeybee colony matrices, Apis mellifera (Hymenoptera: Apidae) to monitor pesticide presence in continental France. Environ. Toxicol. Chem. 30, 103-111.

Chen, J., Tang, B., Chen, H., Yao, Q., Huang, X., Chen, J., Zhang, D., Zhang, W., 2010. Different functions of the insect soluble and membrane-bound trehalase genes in chitin biosynthesis revealed by RNA interference. PLoS ONE 5, e10133.

Coghlin, C., Carpenter, B., Dundas, S., Lawrie, L., Telfer, C., Murray, G., 2006. Characterization and over-expression of chaperonin t-complex proteins in colorectal cancer. J. Pathol. 210, 351-357. 
Corona, M., Robinson, G.E., 2006. Genes of the antioxidant system of the honey bee: annotation and phylogeny. Insect Mol. Biol. 15, 687-701.

Crailsheim, K., Brodschneider, R., Aupinel, P., Behrens, D., Genersch, E., Vollmann, J., Riessberger-Gallé, U., 2013. Standard methods for artificial rearing of Apis mellifera larvae. J. Apic. Res. 52, 1, 1-16.

Cresswell, J.E., Merritt, S.Z., Martin, M.M., 1992. The effect of dietary nicotine on the allocation of assimilated food to energy metabolism and growth in fourth-instar larvae of the southern armyworm, Spodoptera eridania (Lepidoptera: Noctuidae). Oecologia $89,449-453$.

Dani, F.R., Iovinella, I., Felicioli, A., Niccolini, A., Calvello, M.A., Carucci, M.G., Qiao, H., Pieraccini, G., Turillazzi, S., Moneti, G., Pelosi, P., 2010. Mapping the expression of soluble olfactory proteins in the honeybee. J. Proteome Res. 9, 1822-1833.

Davis, A.R., 1989. The study of insecticide poisoning of honeybee brood. Bee World 70, $163-174$.

DeGrandi-Hoffman, G., Hagler, J., 2000. The flow of incoming nectar through a honey bee (Apis mellifera L.) colony as revealed by a protein marker. Insectes Sociaux 47, 302 306.

Derecka, K., Blythe, M.J., Malla, S., Genereux, D.P., Guffanti, A., Pavan, P., Moles, A., Snart, C., Ryder, T., Ortori, C.A., Barrett, D.A., Schuster, E., Stöger, R., 2013. Transient exposure to low levels of insecticide affects metabolic networks of honeybee larvae. PLoS ONE 8, e68191.

Detzel, A., Wink, M., 1993. Attraction, deterrence or intoxication of bees (Apis mellifera) by plant allelochemicals. Chemoecology 4, 8-18.

Dow, J.A.T., Davies, S.A., 2006. The Malpighian tubule: rapid insights from post-genomic biology. J. Insect Physiol. 52, 365-378.

Du Rand, E.E., Pirk, C.W.W., Nicolson, S.W., Apostolides, Z., 2017. The metabolic fate of nectar nicotine in worker honey bees. J. Insect Physiol. 98, 14-22.

Du Rand, E.E., Smit, S., Beukes, M., Apostolides, Z., Pirk, C.W.W., Nicolson, S.W., 2015. Detoxification mechanisms of honey bees (Apis mellifera) resulting in tolerance of dietary nicotine. Sci. Rep. 5, 11779.

Erban, T., Petrova, D., Harant, K., Jedelsky, P.L., Titera, D., 2014. Two-dimensional gel proteome analysis of honeybee, Apis mellifera, worker red-eye pupa hemolymph. Apidologie 45, 53-72. 
Evans, A.M., DeHaven, C.D., Barrett, T., Mitchell, M., Milgram, E., 2009. Integrated, nontargeted ultrahigh performance liquid chromatography/electrospray ionization tandem mass spectrometry platform for the identification and relative quantification of the small-molecule complement of biological systems. Anal. Chem. 81, 66566667.

Feng, M., Ramadan, H., Han, B., Fang, Y., Li, J., 2014. Hemolymph proteome changes during worker brood development match the biological divergences between western honey bees (Apis mellifera) and eastern honey bees (Apis cerana). BMC Genomics $15,563$.

Forêt, S., Wanner, K.W., Maleszka, R., 2007. Chemosensory proteins in the honey bee: insights from the annotated genome, comparative analyses and expressional profiling. Insect Biochem. Mol. Biol. 37, 19-28.

Ghanim, M., Kontsedalov, S., 2007. Gene expression in pyriproxyfen-resistant Bemisia tabaci Q biotype. Pest Manag. Sci. 63, 776-783.

Gregorc, A., Ellis, J.D., 2011. Cell death localization in situ in laboratory reared honey bee (Apis mellifera L.) larvae treated with pesticides. Pestic. Biochem. Physiol. 99, 200207.

Gregorc, A., Evans, J.D., Scharf, M., Ellis, J.D., 2012. Gene expression in honey bee (Apis mellifera) larvae exposed to pesticides and Varroa mites (Varroa destructor). J. Insect Physiol. 58, 1042-1049.

Guedes, R.N.C., Oliveira, E.E., Guedes, N.M.P., Ribeiro, B., Serrao, J.E., 2006. Cost and mitigation of insecticide resistance in the maize weevil, Sitophilus zeamais. Physiol. Entomol. 31, 30-38.

Guidugli, K.R., Hepperle, C., Hartfelder, K., 2004. A member of the short-chain dehydrogenase/reductase (SDR) superfamily is a target of the ecdysone response in honey bee (Apis mellifera) caste development. Apidologie 35, 37-47.

Hawthorne, D.J., Dively, G.P., 2011. Killing them with kindness? In-hive medications may inhibit xenobiotic efflux transporters and endanger honey bees. PLoS ONE 6, e26796.

Haydak, M.H., 1970. Honey bee nutrition. Annu. Rev. Entomol. 15, 143-156.

Heimken, C., Aumeier, P., Kirchner, W.H., 2009. Mechanisms of food provisioning of honeybee larvae by worker bees. J. Exp. Biol. 212, 1032-1035.

Hsu, Y., Chern, J., Cai, Y., Liu, M., Choi, K., 2007. Drosophila TCTP is essential for growth and proliferation through regulation of dRheb GTPase. Nature 445, 785-788. 
Hukkanen, J., Jacob III, P., Benowitz, N.L., 2005. Metabolism and disposition kinetics of nicotine. Pharmacol. Rev. 57, 79-115.

Human, H., Archer, C.R., Du Rand, E.E., Pirk, C.W.W., Nicolson, S.W., 2014. Resistance of developing honeybee larvae during chronic exposure to dietary nicotine. J. Insect Physiol. 69, 74-79.

Isidorov, V.A., Isidorova, A.G., Sczczepaniak, L., Czyżewska, U., 2009. Gas chromatographic-mass spectrometric investigation of the chemical composition of beebread. Food Chem. 115, 1056-1063.

Isman, M.B., 2006. Botanical insecticides, deterrents, and repellents in modern agriculture and an increasingly regulated world. Annu. Rev. Entomol. 51, 45-66.

Johnson, R.M., 2015. Honey Bee Toxicology. Annu. Rev. Entomol. 60, 415-434.

Johnson, R.M., Mao, W., Pollock, H.S., Niu, G., Schuler, M.A., Berenbaum, M.R., 2012. Ecologically appropriate xenobiotics induce cytochrome P450s in Apis mellifera. PLoS ONE 7, e31051.

Johnson, R.M., Wen, Z., Schuler, M.A., Berenbaum, M.R., 2006. Mediation of pyrethroid insecticide toxicity to honey bees (Hymenoptera: Apidae) by cytochrome P450 monooxygenases. J. Econ. Entomol. 99, 1046-1050.

Kim, I., Lee, K.S., Hwang, J.S., Ahn, M.Y., Yun, E.Y., Li, J.H., Sohn, H.D., Jin, B.R., 2006. Molecular cloning and characterization of ATX1 cDNA from the mole cricket, Gryllotalpa orientalis. Arch. Insect Biochem. Physiol. 61, 231-238.

Kliot, A., Ghanim, M., 2012. Fitness costs associated with insecticide resistance. Pest Manag. Sci. $68,1431-1437$.

Kliot, A., Kontsedalov, S., Ramsey, J.S., Jander, G., Ghanim, M., 2014. Adaptation to nicotine in the facultative tobacco-feeding hemipteran Bemisia tabaci. Pest Manag. Sci. 70, 1595-1603.

Köhler, A., Pirk, C.W.W., Nicolson, S.W., 2012. Honeybees and nectar nicotine: deterrence and reduced survival versus potential health benefits. J. Insect Physiol. 58, 286-292.

Kretschmar, J.A., Baumann, T.W., 1999. Caffeine in Citrus flowers. Phytochemistry 55, 1923.

Kumar, P., Pandit, S.S., Steppuhn, A., Baldwin, I.T., 2014. Natural history-driven, plantmediated RNAi-based study reveals CYP6B46's role in a nicotine-mediated antipredator herbivore defense. Proc. Natl. Acad. Sci. USA 111, 1245-1252. 
Labbé, R., Caveney, S., Donly, C., 2011. Expression of multidrug resistance proteins is localized principally to the Malpighian tubules in larvae of the cabbage looper moth, Trichoplusia ni. J. Exp. Biol. 214, 937-944.

Leslie, E., 2001. Toxicological relevance of the multidrug resistance protein 1, MRP1 (ABCC1) and related transporters. Toxicology 167, 3-23.

Li, J., Zhang, L., Feng, M., Zhang, Z., Pan, Y., 2009. Identification of the proteome composition occurring during the course of embryonic development of bees (Apis mellifera). Insect Mol. Biol. 18, 1-9.

Liu, X., Li, F., Li, D., Ma, E., Zhang, W., Zhu, K.Y., Zhang, J., 2013. Molecular and functional analysis of UDP-N-acetylglucosamine pyrophosphorylases from the migratory locust, Locusta migratoria. PLoS ONE 8, e71970.

Li, X., Baudry, J., Berenbaum, M.R., Schuler, M.A., 2004. Structural and functional divergence of insect CYP6B proteins: from specialist to generalist cytochrome $\mathrm{P} 450$. Proc. Natl. Acad. USA 101, 2939-2944.

Li, X., Schuler, M.A., Berenbaum, M.R., 2007. Molecular mechanisms of metabolic resistance to synthetic and natural xenobiotics. Annu. Rev. Entomol. 52, 231-253.

London-Shafir, I., Shafir, S., Eisikowitch, D., 2003. Amygdalin in almond nectar and pollenfacts and possible roles. Plant Syst. Evol. 238, 87-95.

Lu, W., Kang, M., Liu, X., Zhao, X., Guo, X., Xu, B., 2012. Identification and antioxidant characterisation of thioredoxin-like1 from Apis cerana cerana. Apidologie 43, 737752.

Mao, W., Rupasinghe, S.G., Johnson, R.M., Zangerl, A.R., Schuler, M.A., Berenbaum, M.R., 2009. Quercetin-metabolizing CYP6AS enzymes of the pollinator Apis mellifera (Hymenoptera: Apidae). Comp. Biochem. Physiol. Part B 154, 427-434.

Mao, W., Schuler, M.A., Berenbaum, M.R., 2015. A dietary phytochemical alters casteassociated gene expression in honey bees. Sci. Adv. 1, e1500795-e1500795.

Mao, W., Schuler, M.A., Berenbaum, M.R., 2013. Honey constituents up-regulate detoxification and immunity genes in the western honey bee Apis mellifera. Proc. Natl. Acad. Sci. USA 110, 8842-8846.

Mao, W., Schuler, M.A., Berenbaum, M.R., 2011. CYP9Q-mediated detoxification of acaricides in the honey bee (Apis mellifera). Proc. Natl. Acad. Sci. USA 108, 1265712662. 
Martins, J.R., Nunes, F.M., Cristino, A.S., Simões, Z.L., Bitondi, M.M., 2010. The four hexamerin genes in the honey bee: structure, molecular evolution and function deduced from expression patterns in queens, workers and drones. BMC Mol. Biol. 11, 23.

Miwa, S., St-Pierre, J., Partridge, L., Brand, M.D., 2003. Superoxide and hydrogen peroxide production by Drosophila mitochondria. Free Radic. Biol. Med. 35, 938-948.

Mullin, C.A., Frazier, M., Frazier, J.L., Ashcraft, S., Simonds, R., vanEngelsdorp, D., Pettis, J.S., 2010. High levels of miticides and agrochemicals in North American apiaries: implications for honey bee health. PLoS ONE 5, e9754.

Murataliev, M., Guzov, V., Walker, F., Feyereisen, R., 2008. P450 reductase and cytochrome b5 interactions with cytochrome P450: effects on house fly CYP6A1 catalysis. Insect Biochem. Mol. Biol. 38, 1008-1015.

Nielsen, M.D., Luo, X., Biteau, B., Syverson, K., Jasper, H., 2008. 14-3-3ع antagonizes FoxO to control growth, apoptosis and longevity in Drosophila. Aging Cell 7, 688-699.

Niwa, R., Namiki, T., Ito, K., Shimada-Niwa, Y., Kiuchi, M., Kawaoka, S., Kayukawa, T., Banno, Y., Fujimoto, Y., Shigenobu, S., Kobayashi, S., Shimada, T., Katsuma, S., Shinoda, T., 2010. Non-molting glossy/shroud encodes a short-chain dehydrogenase/reductase that functions in the "Black Box" of the ecdysteroid biosynthesis pathway. Development 137, 1991-1999.

Nixon, H.L., Ribbands, C.R., 1952. Food transmission within the honeybee community. Proc. R. Soc. Lond. B Biol. Sci. 140, 43-50.

Ramsey, J.S., Elzinga, D.A., Sarkar, P., Xin, Y.-R., Ghanim, M., Jander, G., 2014. Adaptation to nicotine feeding in Myzus persicae. J. Chem. Ecol. 40, 869-877.

Rattray, A.M.J., Müller, B., 2012. The control of histone gene expression. Biochem. Soc. Trans. 40, 880-885.

Schimmelpfeng, K., Strunk, M., Stork, T., Klämbt, C., 2006. mummy encodes an UDP-Nacetylglucosamine-dipohosphorylase and is required during Drosophila dorsal closure and nervous system development. Mech. Dev. 123, 487-499.

Shimomura, Y., Murakami, T., Nakai, N., Nagasaki, M., Harris, R.A., 2004. Exercise promotes BCAA catabolism: effects of BCAA supplementation on skeletal muscle during exercise. J. Nutr. 134, 1583S-1587S.

Singaravelan, N., Inbar, M., Ne'eman, G., Distl, M., Wink, M., Izhaki, I., 2006. The effects of nectar-nicotine on colony fitness of caged honeybees. J. Chem. Ecol. 32, 49-59. 
Singaravelan, N., Nee'man, G., Inbar, M., Izhaki, I., 2005. Feeding responses of free-flying honeybees to secondary compounds mimicking floral nectars. J. Chem. Ecol. 31, $2791-2804$.

Smodiš Škerl, M.I., Kmecl, V., Gregorc, A., 2010. Exposure to pesticides at sublethal level and their distribution within a honey bee (Apis mellifera) colony. Bull. Environ. Contam. Toxicol. 85, 125-128.

Snyder, M.J., Walding, J.K., Feyereisen, R., 1994. Metabolic fate of the allelochemical nicotine in the tobacco hornworm Manduca sexta. Insect Biochem. Mol. Biol. 24, 837-846.

Steppuhn, A., Gase, K., Krock, B., Halitschke, R., Baldwin, I.T., 2004. Nicotine's defensive function in nature. PLoS Biol. 2, e217.

Tadmor-Melamed, H., Markman, S., Arieli, A., Distl, M., Wink, M., Izhaki, I., 2004. Limited ability of Palestine sunbirds Nectarinia osea to cope with pyridine alkaloids in nectar of tree tobacco Nicotiana glauca. Funct. Ecol. 18, 844-850.

Tomizawa, M., Casida, J.E., 2003. Selective toxicity of neonicotinoids attributed to specificity of insect and mammalian nicotinic receptors. Annu. Rev. Entomol. 48, 339-364.

Voet, D., Voet, J.G., Pratt, C.W., 2013. Chapter 15: Glucose catabolism, in: Fundamentals of Biochemistry: Life at the Molecular Level. John Wiley \& Sons, Inc., pp. 472-514.

Vogel, C., Marcotte, E.M., 2012. Insights into the regulation of protein abundance from proteomic and transcriptomic analyses. Nat. Rev. Genet. 13, 227-232.

Wink, M., Theile, V., 2002. Alkaloid tolerance in Manduca sexta and phylogenetically related sphingids (Lepidoptera: Sphingidae). Chemoecology 12, 29-46.

Winston, M.L., 1987. The biology of the honey bee. Harvard University Press, Cambridge, Massachusetts, USA.

Wittstock, U., Agerbirk, N., Stauber, E.J., Olsen, C.E., Hippler, M., Mitchell-Olds, T., Gershenzon, J., Vogel, H., 2004. Successful herbivore attack due to metabolic diversion of a plant chemical defense. Proc. Natl. Acad. Sci. USA 101, 4859-4864.

Wittstock, U., Burow, M., 2007. Tipping the scales - specifier proteins in glucosinolate hydrolysis. IUBMB Life 59, 744-751.

Wu, J.Y., Anelli, C.M., Sheppard, W.S., 2011. Sub-lethal effects of pesticide residues in brood comb on worker honey bee (Apis mellifera) development and longevity. PLoS ONE 6, e14720. 
Yang, J., McCart, C., Woods, D.J., Terhzaz, S., Greenwood, K.G., ffrench-Constant, R.H., Dow, J.A.T., 2007. A Drosophila systems approach to xenobiotic metabolism. Physiol. Genomics 30, 223-231.

Yao, P., Chen, X., Yan, Y., Liu, F., Zhang, Y., Guo, X., Xu, B., 2014. Glutaredoxin 1, glutaredoxin 2, thioredoxin 1, and thioredoxin peroxidase 3 play important roles in antioxidant defense in Apis cerana cerana. Free Radic. Biol. Med. 68, 335-346.

Yao, P., Hao, L., Wang, F., Chen, X., Yan, Y., Guo, X., Xu, B., 2013. Molecular cloning, expression and antioxidant characterisation of a typical thioredoxin gene (AccTrx2) in Apis cerana cerana. Gene 527, 33-41.

Zhang, J., de Toledo, S.M., Pandey, B.N., Guo, G., Pain, D., Li, H., Azzam, E.I., 2012. Role of the translationally controlled tumor protein in DNA damage sensing and repair. Proc. Natl. Acad. Sci. USA 109, E926-E933.

Zhu, W., Schmehl, D.R., Mullin, C.A., Frazier, J.L., 2014. Four common pesticides, their mixtures and a formulation solvent in the hive environment have high oral toxicity to honey bee larvae. PLoS ONE 9, e77547. 